\title{
Curriculum Design and Implementation: Resources, Processes and Results
}

\author{
Margaret McMillan ${ }^{1}$, Penelope Little ${ }^{1}$, Jane Conway ${ }^{2}$, Annette Solman ${ }^{3}$ \\ ${ }^{1}$ School of Nursing and Midwifery, University of Newcastle, Australia \\ ${ }^{2}$ Dean Teaching \& Learning, Faculty of Medicine \& Health, UNE, Armidale, NSW, Australia \\ ${ }^{3}$ NSW Higher Education Training Institute Adjunct Professor, University of Technology, Sydney, NSW, Australia
}

Purpose: To conduct critical reviews of two current health professional programs to test alignment of implementation efforts and governance processes to student, academic and industry expectations and outcomes; To make recommendations for curriculum design and implementation that optimize alignment of course/unit processes and outcomes to expectations of stakeholders.

Methods: Workshops and iterative processes document analysis, comparative appraisal of website program offerings, analysis of graduate survey responses, literature reviews.

Results: Implicit in renewal processes were intentions to align to Faculty Vision, ensure viability of offerings, improve responses to student and service needs and monitor impact of design choices on resources.

Conclusion: Improving alignment of strategies with curriculum design were reliant on good governance of implementation, management of resources supporting learning. Review processes require collaboration between reviewers and members of academic units, consideration of extent of achievement of shared expectations around learning and teaching activities and appraisal of realistic expectations of curriculum.

Keywords: Curriculum review; Student-centred learning; Academic workloads

\section{INTRODUCTION}

Societal expectations demand graduates from contemporary higher education who have attributes consistent with the needs of informed citizenship and professional practice; this entails the capacity to apply critical thinking to a range of contexts. The purpose of the latter centers on the ability of graduates to embrace and enhance outcomes relevant to society and their professional practice. Any review of published graduate attributes in Australia shows common elements: Critical thinking, enquiry/problem-solving, communication skills that facilitate constructive negotiations around change, information fluency, global citizenship, professional practice. Despite the opportunity to capitalize on a variety of ways of implementing these ideas, there are common elements for success in achieving these. The single most important is the need to ensure a learner-centered approach that gives the student the 'know-how' to become life-long learners as citizens and reflective practitioners.

As experienced educators ourselves the authors have participated in all aspects of curriculum design, accreditation, implementation, formative renewal, evaluation, and review. In all endeavors, over time, certain elements emerge as critical to the development of learner-centered approaches required to satisfy the required curriculum and graduate outcomes. Our particular educational philosophical approach includes the following principles:

(C) Copyright 2019 International Society for Problem-Based Learning

(c) This is an Open Access article distributed under the terms of the Creative Commons Attribution Non-Commercial License (http://creativecommons.org/licenses/ by-nc/4.0/) which permits unrestricted non-commercial use, distribution, and reproduction in any medium, provided the original work is properly cited. 
- The context must reflect how the discipline informs the everyday life and/or professional practice; the students can see the relevance and thus engage more readily in the learning event

- The stimuli for learning need to be initiated with student engagement in mind; the material aims to provoke students to see alternative responses to situations thus engaging in enquiry

- The notion of self-directed, peer and facilitated learning is central to the methodology that embeds life-long learning

Building sound communication strategies enables students to identify issues and make a constructive response that is defensible through evidence that supports improvement/change for systems and clients

Frameworks for critical thinking and reflective practice need to be made explicit in all learning endeavors if students are to emerge as constructive contributors to society and professional practice.

While curriculum review methodologies may differ, the expression of the above principles should be evident to the review in both curriculum documents and implementation processes and outcomes. While this is our lens through which we achieve sound educational design and outcomes, it necessarily requires institutional support through appropriate governance and adequate resources (human and other) that are cognisant of student and staff workloads.

This paper centers on the authors' experience with reviews of postgraduate studies across the Australian higher education sector. However, the issues raised in two exemplars to curriculum renewal apply to a review of any curriculum development initiative. The authors suggest that both at the design and implementation stages, insufficient consideration is given to the impact of decisions on the student experience and identification of appropriate human and other resources needed for good governance in pursuit of sustainable implementation processes, outcomes and results consistent with the attainment of the stated graduate profiles.

\section{Standards for Curriculum Renewal: Expectations and outcomes}

In a similar way to accreditation bodies across the world, the Tertiary Education Quality Standards Agency (TEQSA) in Australia establishes the criteria for accreditation of education providers and programs; recent renewal of standards reflected the importance they placed the student learning experience and the required resources that need to be available to support successful learning outcomes. Different professions also have standards that inform program accreditation processes. Generally, curriculum reviewers are required to respond with details of processes and outcomes since the last review in formal templates and members of other health professional accreditation panels also typically seek evidence of outcomes against those criteria.

While TEQSA and professional accreditors do not express a view on curriculum design, the focus is on all aspects of gover- nance within approaches to implementation; choices around instructional design influence the latter. The main aims for accreditors are to ensure quality in student activities and outcomes, establish reasonable expectations around resources for academics and to promote evidence-based approaches to the management of educational processes that incorporate preparation for professional practice. A workload model is required by the TEQSA so that students are assured of adequate resources to meet the outcomes specified in the accredited program. Workload models ensure that academic roles and responsibilities are clear and development and implementation effort are distributed equitably and transparently across academic staff members. Models underpinned by established principles are now widely used across the higher education sector. These are significant in informing mutual expectations among directors within organizations, educators, program and course coordinators, and student support teams about work and work practices.

\section{Two cases of curriculum renewal are reported on in this paper:}

Case 1 is an Australian University offering a range of options for Masters programs, including mental health, with exit points at Graduate Certificate or Graduate Diploma Level. Like most universities, these postgraduate programs for Australian students involved online offerings with some intensive face-to-face study days. International students need to comply with regulations that include participation in on-campus offerings.

Case 2 involved an organization that services health professional development state-wide. This organization had recently successfully acquired initial accreditation by TEQSA to offer Masters level studies (with exit points) focussed on professional preparation to respond to a range of patient/client experiences in mental health and illness.

The programs' Conceptual Frameworks were consistent with contemporary postgraduate education design for medical and other health professionals, the frequent use of blended (including online) modes of delivery, and a recognition of a need to reflect alignment to clinical practice.

\section{Literature review}

\section{Curriculum design and student learning outcomes}

Postgraduate education in health professional education in Australia has continued to grow since the 1990s. However, Sandars et al. (2015) suggest that "often the use of educational theory to inform (curriculum) design is not made explicit". They noted that the professional development of educators needs to include an understanding of their practice if they are to promote meaningful 
learning, especially when technology is involved in the learning processes. An educational theory they add, can provide answers to the question "What type of learner do I want to develop?"

Reviews of suites of Australian online offerings in the health professions across Higher Education providers show a consistent trend towards rationalization of course/subject offerings. The need to consider stakeholders' returns on investment in the postgraduate study was also apparent; Ng et al. (2014) focused on educational outcomes. They used Barr et al. 's (1999) Evaluative Framework to begin their exploration of student perceptions of educational experiences:

- Learner's reaction - the learners' views of their learning experience and satisfaction with their training and education

- Changes in attitudes and perceptions - towards patients and their carers

Acquisition of knowledge and skills - the acquisition of concepts, procedures, and principles of working with specific patient groups, and the acquisition of critical thinking and problem solving, intervention skills, and team working skills

Changes in behavior - implementing Learning in the workplace, as a result of changes in attitudes and perceptions, or the application of newly acquired knowledge and skills.

Changes in organizational practice - wider changes in health care delivery

Benefits to patients and carers - improvement to their health and well-being

Ng et al. (2014) queried the extent to which there is any evidence of changes in attitude or measures of change in practice but some evidence of knowledge and skill acquisition as a result of the completion of postgraduate studies. Online information available on exit surveys of Australian students shows a trend for around $80 \%$ of graduate satisfaction with their study experience irrespective of place of enrolment or enrolment numbers (Quality Indicators for Learning and Teaching - QILT 2016). However, enrolment figures, time for completion, and attrition rates also warrant careful consideration; these figures are not readily available to the public. It is also important to note that these data sets on graduate satisfaction do not consider the intent expressed in program objectives against outcomes consistent with the needs of professionals within actual practice.

\section{E-Learning and impact on educators}

Kirkwood and Price (2014) undertook a literature review around the term e-learning; the concept subsumes both the application of information and communication around both learning and teaching strategies. They suggested that often the wrong questions about the value of online versus face to face learning questions are posed and recommend asking: "How can we design technology that enhances learning, and how can we measure that en- hancement?" The answer to this question is more likely to focus on the things that add value to the learners' experiences while at the same time identifying how to innovate rather than merely sustaining old practices in a technological environment: "Many of the studies reviewed concentrated on the means of replicating and supplementing existing teaching". The aim of enhancing learning and achieving transformation through the use of technology is often not fully explored. This can make academic activities more complex without a satisfactory return on investment.

One can see from a survey undertaken by Henderson et al. (2017) that digital technologies are now a central feature of the student experience of higher education. However, Englund et al. (2017) suggested that 'teachers' conception of and approaches to teaching are central for the successful implementation of educational technologies in higher education". In their research, the senior teachers experienced the most difficulty in adapting to this change. Less experienced teachers had fewer preconceptions of teaching responsibilities and thus were more likely to embrace innovation and be more student-centered; the transformational potential for educational technology, therefore, might be limited without appropriate professional development.

Mimirinis (2018) looked more closely at academics' conceptions of e-assessment. While assessment is recognized as a major driver of student learning and higher education institutions have more recently moved towards the use of more standardized assessment processes. In part, this has arisen because of the need for mechanisms to deal with the re-use of material in the online environment, ie, plagiarism and the need to be assured of the authenticity of the students' work. Referring to assessment literacy among academics, this author discusses issues of fairness, consistency, storage, and quality assurance processes. There was nevertheless a belief that technology could enhance the likelihood that assessment equates to learning.

Delgaty (2013) undertook a meta-analysis of e-learning involving health care professionals, describing a successful online initiative from the student perspective but involving an arduous path for academics; she noted the failure of the literature to describe elements of context. The main difficulties she described were experienced by academic, technical, and administrative staff — issues centered on the time involved in the curriculum implementation, particular responsibilities, and distribution of labor. Her research examining time spent by staff - analysis of email traffic, self -reported work logs, and web analytics resulted in a recommendation to look more closely at the nature and levels of guidance needed around workload patterns and the use of resources. There were tensions in her experience between 'top-down e-learning strategies' and 'bottom-up' creativity and innovation. Recommenda- 
tions included a careful appraisal of the timing of desirable support interventions, investment in training for academics to focus on their role when reliant on e-learning. Consideration of both academic and administrative issues and being vigilant about technical support. While Delgaty's team were changing their model of learning, they also needed to change their model of working.

Henderson et al. (2017) note that from a 'logistical' perspective, the outcomes for students involved in e-learning are positive, but the 'transformation' of elements of the teaching and learning experience is not substantial. Survey responses suggest students are making good use of technologies: i) The Learner Management Systems were valued - technology assisted with organization and management of studies, staying on track, keeping up to date ii) there was greater flexibility in time and choice of places of study iii) time saving arose from capacity for revision and review, viewing information from multiple perspectives and ease of access to resources. These findings relate to outcomes that reflect greater autonomy and independence and self-direction in learning. However, Henderson et al. (2017) suggest there are numerous expansive, challenging, empowering, and enlightening ways that technologies could be used. This might require more thought be given to institutional practices and expectations if more active and participatory educational outcomes are to be achieved.

\section{Workloads}

Mundt (2009) made a critical point over a decade ago when she wrote:

faculty members and administrators have not reached agreement about what constitutes an appropriate workload. This statement reflects the essence of the academic workload problem and highlights the tension that exists between individual and organizational goals. Faculty members and administrators must come to a collective agreement about the relative value of different activities and the allocation of resources to achieve outcomes at the macro level as well as at the individual level.

This challenging situation persists. However, when administrators and academics have attempted to put agreed principles into a model that reflects academic scholarly efforts (Cohen et al., 2009), there is a risk of creating a system that is excessively detailed. Utz (2009) suggested that academics should celebrate the flexibility implicit in the work of teaching, research and service. Nevertheless, in 2015, Bezuidenhout reported on the changing academic roles and functions and resulting workloads, noting the demands of curriculum renewal, the potential to make oneself available over 24 hours, the demands for student support and changes in staff to student ratios; these factors it was argued have impacted academic freedom. She makes the point that there is a difference between the quantitative and qualitative elements of monitoring workload.

Acton et al. (2015) focused on increasing involvement in simulated learning situations in medical education and acknowledged the power of the innovations in this area, especially for the learner. They argued however, that simulations increased the time commitment of medical faculty and proposed strategies for compensation.

Cook and Ellaway (2015) also examined medical education and recommended use of the Stufflebeam's CIPP (Context, Input, Process, Product) model of evaluation following a needs analysis at the formative stage of innovation. This, they said, might help to identify the significant issues around the uptake of technology-enhanced learning approaches. However, understanding what is 'enhanced' through the use of technology warrants consideration.

Schneckenberg (2009) highlighted expectations for academics to play a major role in innovation efforts, especially those involving the uptake of information technologies. This is not unreasonable, for example, in the cases involving health professional education described here, where there are demands in the workplace for information fluent health service personnel. However, they cautioned that there are habitual traits evident in an academic profile and "long-standing cultural values" that impact on motivation and levels of engagement with e-learning strategies. Haggerty (2015), focusing on four applied science degrees, suggested that academic workloads are affected by many variables, and thus it is difficult to measure these in isolation. She noted that new educators had limited access to professional development during their orientation. The latter, when available, focused on technological aspects and failed to deal with the pedagogy in e-learning practices. This lack of preparation increases workload and thus is time consuming, given that it adds to the complexity with any real appreciation of what needs to happen.

\section{METHODS}

Both case reviews involved iterative processes reliant on emergent themes from literature reviews, outcomes of participation of academic unit personnel in workshops, data from focus groups, interviews with key informants, and surveys that informed an appreciation of graduate experiences.

Curriculum reviewers and developers began by considering their assumptions and perceptions of their professional experiences around contemporary education and practice. Implications arising from the contemporary literature and data from across the sector (including websites) also informed the direction for processes of review.

Staff assumptions and perceptions will always influence subse- 
quent actions around efforts for curriculum renewal or redesign; processes around program implementation and clarity about roles and functions of those involved in curriculum development and implementation also needed to be made explicit. Ultimately any redesign in an ideal world should contribute to agreed educational outcomes, efficiencies in processes, the achievement of realistic workloads, and accommodate the complex and multi-faceted variables that influence student and staff members' workloads.

\section{RESULTS}

The two case studies achieved a high level of congruence with the principles outlined above. Both needed to review their design and delivery to achieve greater focus on for learner-centered learning in a way that was not limited only to choice and flexibility for students. Students need to be recognized as adult learners with professional experience.

There was clear evidence from the websites and literature, documents on program offerings, data from workshops and focus groups of

- recognition of a need for renewal of designs and rationalization of the range of courses or units offered in postgraduate studies in mental health across the higher education sector in Australia,

- an increasing trend for blended learning involving more sophisticated online Learner Management Systems,

- curriculum design and models of care increasingly reliant the online environment that puts the consumer (client or student) at the center of care and educational aspirations for greater integration of processes and practices,

- an exploration of the macro factors that drive curriculum development and implementation and the impact on workload:

Contextual factors; profiles of potential students; profiles of staff the experienced (often clinicians) but traditionally oriented versus information fluent, younger academics; members of both groups are often less well appraised of pedagogy

consideration of the place of all health professionals in contemporary contexts and care and subsequent identification of a suite of abilities applicable to more integrated educational offerings

- the potential for postgraduate studies as educational preparation for more advanced practice and application of similar offerings to a range of health service personnel

- a search for answers to the question that clinicians might ask: Why study further? Why enroll in this particular program? Answers should lead to consideration of the potential impact on future student numbers and program offerings

emerging patterns in e-Learning impacting curriculum design and implementation: Perceptions of outcomes - personal, professional and workplace: Clear descriptions of academic, administrative and technical roles and functions

implications of contextual factors for demand for resources and staff workloads: This was seen to be impacted by organizational vision and strategy, curriculum design, patterns of enrolment, nature, and extent of integration of concepts, approaches to assessment, implementation of online initiatives, clarity in description of roles and functions in academic/administrative/technological activities around curriculum development and implementation.

Emergent themes within the results of review processes undertaken by the organizations' personnel were used by the external reviewers: These centered on clarification of strategic intent, implications for choices in curriculum structures that inform and are informed by conceptual frameworks, consideration of the impact of choices on curriculum implementation, clarification of roles and functions across academic, administrative and technical responsibilities. These are now elaborated upon.

\section{Strategic Directions}

Examination of stated organizational intentions about the future need to be made explicit so that governance processes for curriculum implementation also reflect the achievement of all elements of vision and mission statements. At an appropriate time within the accreditation cycle, there is an opportunity to revisit earlier decisions that have impacted the current programs and their implementation. So often, what follows curriculum development is a period of disruption eg, as a result of technological innovation creating demand for intense activity around course development. Mid-cycle is timely for careful reconsideration of earlier decisions that impact subsequent decisions around the way forward.

The conceptual framework/s should reflect a particular strategic strength of the education provider but also the reality of contemporary integrated practice; significant strategic strengths provide an opportunity for course offerings being offered in common across a range of disciplines. This also facilitates the better use of content experts that will attract greater interest in enrolling in programs reflecting advanced practice skill development in response to the needs of consumers experiencing particular symptoms. Separate reports on governance could be required to respond to specific professional accreditation requirements to ensure appropriate responses to context, application to discipline-specific roles, and details of outcomes of the practice-based assessment.

\section{Curriculum Structure}

Any existing or proposed health professional postgraduate education design, including exit points and modes of delivery, need to reflect alignment to contemporary clinical practice. The impact of choices around the design of opportunity for students to 'specialize' will impact on the total number of course units on offer. The complexity of administration and teaching activities means that programs will not be sustainable unless there are viable student enrolments. Critical decisions should, therefore, include resource implications of using particular curriculum frameworks and structures. 


\section{Curriculum Implementation}

Organizational strengths in online delivery need to be extended to ensure the provision of course offerings consistent with higher education standards, professional development initiatives, and student expectations. This could be especially useful for the cost-effective development of fixed resource sessions eg, Lectures provided by content experts, that are often problematic because of the availability of personnel and time constraints. Use of other institutional resources included professional development on blended and online learning initiatives eg, Professional Development Programs that model facilitative styles and contemporary learning initiatives or Graduate Certificates in Tertiary Teaching offered by Learning and Development Centres.

\section{Administration and Teaching/Learning support}

The extent to which administrative support is aligned to student or academic needs in a manner that is efficient and effective was interrogated. The functions identified in position descriptions while comprehensive, sometimes involve elements of duplication and redundancy.

Redefinition of the academic support roles and functions need to be re-aligned to administrative roles and functions informed by a student-focused needs assessment across the academic calendar eg, Admissions and Student enrolments, progression and attrition; Assessment; Learning and development referrals for Academic decisions; Information Technology referrals, General Enquiries.

Academic, administrative responsibilities need to be clearly defined and separated from the support officer's responsibilities. There was also evidence of a blurring of academic staff and support personnel responsibilities. Ultimately, the academic must be responsible for student learning activities and assessments.

\section{Levels of Governance}

Following any decisions on curriculum renewal, processes and responsibilities for levels of responsibility for matters of governance need to be clarified before decisions on load attributed to effort: The educational leadership and governance roles, program, course/unit co-ordination roles, and responsibilities need to be clarified and boundaries maintained.

The contractual agreement at enrolment between the student and the institution should be consistent with the accredited program, and therefore governance efforts must ensure its consistency with the appropriate award levels and internal consistency among objectives, learning events, and assessment. Therefore, the authority for decision-making must be apparent.

\section{CONCLUSIONS}

In order to make decisions on whether to refresh, renew or abandon particular elements of a program, curriculum developers also need to consider both the impact of their decisions on achievement of the learning outcomes reflected in the graduate profile and the extent to which those decisions are informed by the principles outlined above. Their approach to the management of staff members' workload associated with learning and teaching and other scholarly activities also warrants careful consideration with the sustainability of preferred design in mind. This requires consideration of the required human and material resources attributed to academic, administrative, and technical elements necessary for sound, sustainable program implementation. In an era of greater access to higher education, greater cultural diversity within student and health service clientele, technology-enhanced education and practice, and an orientation towards practice-based curriculum design, thoughtfulness about sound design and governance of curriculum implementation is warranted.

To conclude, the reviewers are expected to make recommendations for quality assurance and quality improvement and consider the sustainability of existing and future resources that support students' experiences.

\section{ACKNOWLEDGEMENTS}

None.

\section{REFERENCES}

Acton, R.D., Chipman, J.G., Lunden, M., \& Schmitz, C. (2015). Unanticipated Teaching demands rise with Simulation Training: Strategies for managing faculty workload. Journal of Surgical Education, 72(3), 522-529.

The Department of Education and Training. (2016). Quality Indicators for Learning and Teaching (QILT) for students to access. https://www.qilt.edu.au/

The Department of Education and Training. (2016). https://internationaleducation.gov.au/

Barr, H., Freeth, D., Hammick, M., Koppel, I., \& Reeves, S. (1999). Evaluating interprofessional education. London: A United Kingdom review for health and social care.

Bezuidenhout, A. (2015). Implications for academic workload of the changing role of distance educators. Distance Education, 36(2), 246-262.

Cohen, M.Z., Hickey, J.V., \& Upchurch, S.L. (2009). Faculty workload calculation. Nursing Outlook, 57(1), 50-9. 
Cook, D.A., \& Ellaway, R.H. (2015). Evaluating Technology Enhanced Learning: A Comprehensive Framework. Medical Teacher, 37(10), 961-970.

Delgaty, L. (2013). A Critical examination of the time and workload involved in the design and delivery of an e-module in postgraduate clinical education. Medical Teacher, 35(5), e1173-e1180.

Englund, C., Anders, D., Price, O., \& Price, P. (2017). Teaching with technology in higher education: Understanding conceptual change and development in practice. Higher Education Research and Development, 36(1), 73-87.

Haggerty, C.E. (2015). Supporting academic workloads in online learning. Distance Education, 36(2), 196-209.

Henderson, M., Selwyn, N., \& Aston, R. (2017). What Works and Why? Student perceptions of 'useful' digital technology in university teaching and Learning. Studies in Higher Education, 42(8), 1567-1579.

Kirkwood, A., \& Price, L. (2014). Technology Enhanced Learning and teaching in higher education: What is 'enhanced' and how do we know? A critical literature review. Learning Media and technology, 39(1), 6-36.

Mimirinis, M. (2018). Qualitative differences in academics' conceptions of e-assessment. Assessment and evaluation in higher education, 44(2), 233-248.
Mundt, M. H. (2009). Commentary: A dean's response to the Cohen, Hickey, and Upchurch article on faculty workload calculation. Nursing Outlook, 57(1), 60-62.

Ng, L., Eley, R., \& Tuckett, A. (2016). Nurses' Pursuit of Postgraduate Education. Nursing and Health Sciences, 18(4), 435-441.

Ng, L.C., Tuckett, A.G., Fox-Young, S.K., \& Kain, V.J. (2014). Exploring registered nurses' attitudes towards postgraduate education in Australia: An overview of the literature. Journal of Nursing Education and Practice, 4(2), 162-170.

Sandars, J., Patel, R., Goh, P.S., Kokatailo, P.K., \& Lafferty, N. (2015). The Importance of Educational Theories for facilitating Learning when using technology in medical education. Medical Teacher, 37(11), 1-4.

Schneckenberg, D. (2009). Understanding the real barriers to technology enhanced innovation in higher education. Educational Research, 51(4), 411-424.

The Tertiary Education Quality Standards (TEQSA). (2015). Higher Education Standards Framework 2015. http://www.teqsa.gov.au/regulatory-approach/higher-education-standardsframework

Utz, S. (2009). Commentary: A Faculty Perspective on faculty workload. Nursing Outlook, 57(1), 63-64. 